\title{
Realising visions for future cities: an aspirational futures methodology
}

Chris D. F. Rogers Eur Ing, BSC, PhD, CEng, MICE, FCIHT, SFHEA Professor of Geotechnical Engineering and Director, UKCRIC National Buried Infrastructure Facility, University of Birmingham, Birmingham, UK

\author{
Dexter V. L. Hunt MEng (Hons), PhD, PGCHE, FHEA \\ Lecturer, University of Birmingham, Edgbaston, Birmingham, UK \\ (corresponding author: c.d.f.rogers@bham.ac.uk)
}

Providing for the future needs of society requires civil engineers to envision the far future, embrace the concepts of sustainability, resilience, smartness, liveability and adaptability, and work collaboratively with all urban professionals and policy-makers. Given that most people live, and societies operate, in cities, visions for future cities often inform the civil engineer's 'brief'. The UK Foresight Future of Cities project and Liveable Cities research consortium combined to create a novel aspirational futures methodology to help define this brief. This paper describes the methodology, which entails co-creation of three extreme aspirational futures, and its application to Bristol and Birmingham, thereby demonstrating the influence of different historical and current contexts. It explores how an engineering intervention - green infrastructure corridors to facilitate urban mobility - if conceived and designed with the intention of delivering multiple benefits, can meet many economic, social and environmental aspirations of a city and it citizens. Discussed in relation to current research and a Policy Commission on Future Urban Living, the results demonstrate the potential to transform engineering value propositions by using robustly-constructed, far-future scenarios to enable all urban professionals to make better, joined-up decisions in harmony with all urban systems, the outcomes being uniquely well-informed alternative business models.

\section{Introduction}

The conceptualisation, planning, preparation and realisation of any 'future city' is a complex but necessary requirement in a world where cities transition, transform, shrink, expand and evolve. This contextual change means that the next generation of future cities will look and operate very differently from today's cities. It is therefore essential that civil engineers, working collaboratively with all other urban professionals to significantly shape their form and operations, should not be constrained by either their ability to, or their freedom to, envision the 'far' future (i.e. $>50$ years) and choose more beneficial pathways towards a range of aspirational goals. The question is: how might such a process be facilitated?

\subsection{Looking to the (far) future}

Futures thinking is not new (Dunn et al., 2015) and a range of 'Foresighting' approaches have been developed (e.g. GOfS, 2018a), not least because they can manifestly enhance the efficacy of decision making in the face of significant uncertainty (GOfS, 2018b; HM Government, 2014). They include

(a) Trend analysis (GOfS, 2009). Trends define broad patterns of change by extrapolating historical trends into the future using different assumptions. Trend analysis is therefore helpful in exploring likely levels of service demand and supply assuming that the basic paradigm to which it is applied broadly remains the same, and for this reason, it is useful for shorter-term planning. Its use diminishes, however, for longer-term thinking where transformational change would render the results suspect, at best, and more likely of very little value at all.

(b) Horizon scanning (Curry et al., 2005; EA, 2006; Foresight, 2003; GOfS, 2017a, 2017b; NERR, 2009). This refers to a systematic examination of information to identify potential threats, risks, emerging issues and opportunities. It is widely used by the UK Government, for example, to assist in planning over a large range of time frames. The ideas that it reveals can be helpful in shaping future scenarios, yet its description as the first step in an evidence-gathering process GOfS (2017a, 2017b) implies that it is unlikely to prove definitive.

(c) Side-swipes or black swans (GOfS, 2009; Hajkowicz and Moody, 2010). Sometimes termed wildcards, these are wholly unexpected events and are succinctly referred to as high-impact, low probability, and yet plausible, events. Since they are usually considered to be extreme outliers, they are often overlooked in rational analysis; however, if they are indeed deemed plausible in the context being considered, they can be helpful as inclusions in scenario thinking. Nevertheless, as with horizon scanning, they are of little use in isolation and should therefore be treated also as part of the process of evidence gathering.

(d) Scenarios analysis (Karlsen and Øverland, 2012; Miles, 2005)

(i) 'Extreme yet plausible' scenarios (Lombardi et al., 2012; Raskin, 2005; Rogers et al., 2012). These scenarios lie at the edge of societal 'plausibility space'; that is they remain recognisable in terms of the way societies operate - scenarios that involve total societal 
breakdown are generally of little value in advancing civil engineering system interventions, for example and yet they describe situations in which one aspect of societal behaviour typically dominates. Four extremes, in which economic forces, societal governance, environmental concerns and control over resources provide the dominant features, are listed in Table 1.

(ii) 'Drivers matrix' (Ogilvy, 1995; Schwartz, 1991; Van der Heijden, 2005). This involves the selection of two drivers of change in relation to the topic under consideration - usually one representing high impact and one high uncertainty - plotting these orthogonally to create four quadrants and then exploring alternative futures in relation to their position on these axes (and hence quadrants). Although this exercise can be repeated with different sets of axes to address the same situation, the mere fact that two drivers are chosen for any one analysis means that other drivers do not receive the same consideration and this might limit the breadth or cohesiveness of thinking.

(iii) 'Aspirational scenarios' or 'success scenarios' (Bezold, 2009a, 2009b, 2010).

While a combination of these approaches should be used (for an overview, see GOfS, 2018a; Hunt and Rogers, 2016a; Hunt et al., 2012), this paper focuses on aspirational scenario approaches (diii), which are reviewed hereafter. A novel methodological approach involving clustering a city's aspirations and using each cluster to inform three extreme future visions for that city (see Hunt and Rogers, 2016b, for its initial manifestation) is then presented, and tested by application to case studies in Birmingham and Bristol, to reveal unique insights from 'what

Table 1. Methods for developing scenario logics

\begin{tabular}{|c|c|c|}
\hline Method & Details/Examples & References \\
\hline Axes-of-uncertainty & $\begin{array}{l}\text { Sometimes referred to as the 'drivers matrix' approach, two } \\
\text { main drivers of uncertainty are selected from step } 4 \\
\text { (Figure 1) to be placed on orthogonal axes with ranging } \\
\text { scales leading to four quadrants or scenarios - one least } \\
\text { preferred and one, diametrically opposite, most preferred } \\
\text { (or aspirational). For this to be effective, the two drivers } \\
\text { should ideally dominate the situation being considered. One } \\
\text { obvious criticism of this approach is that the other drivers } \\
\text { are in danger of being overlooked. }\end{array}$ & $\begin{array}{l}\text { Schwartz (1991), Ogilvy (1995), Van der Heijden (2005), } \\
\text { GOfS (2009), OST (2002), GOfS (2004, 2005, 2010), } \\
\text { Hunt et al. (2012), Zadeh et al. (2014), } \\
\text { Angheloiu et al. (2017). }\end{array}$ \\
\hline $\begin{array}{l}\text { An aspirational } \\
\text { futures approach }\end{array}$ & $\begin{array}{l}\text { Multiple drivers selected from step } 4 \text { are used to create a } \\
\text { small number of (usually at least three) scenarios. For } \\
\text { example: } \\
\text { Conventional expectation (i.e. trend analysis). } \\
\text { Growing desperation (based on a list of major city } \\
\text { challenges). } \\
\text { High aspiration (based on visionary strategies leading to } \\
\text { successful outcomes). }\end{array}$ & $\begin{array}{l}\text { Bezold (2009a, 2009b, 2010), Markley (2015), } \\
\text { IAF (2015). }\end{array}$ \\
\hline Scenario archetypes & $\begin{array}{l}\text { Multiple drivers (adopted from step 4) and 'historical } \\
\text { archetypes' that exist across history in a range of } \\
\text { geographical/cultural settings are used to generate a small } \\
\text { number of (usually at least three) scenarios. For example } \\
\text { Business as usual - a society that continues on the same } \\
\text { path } \\
\text { Disciplined - a society stabilised by ideological values } \\
\text { Transformational - a highly transformative society beyond } \\
\text { what society knows and does now (this is typically the } \\
\text { aspirational scenario). } \\
\text { Collapse - a less hopeful societal failure }\end{array}$ & $\begin{array}{l}\text { Dator (2002), Raskin (2005), Inayatullah (2008), } \\
\text { Inayatullah et al. (2009), Bezold (2009a), } \\
\text { Boyko et al. (2012), Hunt et al. (2012), } \\
\text { Lombardi et al. (2012), Rogers et al. (2012). }\end{array}$ \\
\hline $\begin{array}{c}\text { Extreme-yet- } \\
\text { plausible } \\
\text { scenarios }\end{array}$ & $\begin{array}{l}\text { These scenarios lie on the edge of a 'future urban plausibility } \\
\text { space' - demonstrating extremes of societal behaviour in } \\
\text { different directions of travel from today. The Urban Futures } \\
\text { research consortium adopted four of the six scenarios } \\
\text { produced by the Global Scenarios Group (avoiding scenarios } \\
\text { involving societal breakdown): } \\
\text { Market forces } \\
\text { Fortress world } \\
\text { Policy reform } \\
\text { New sustainability paradigm }\end{array}$ & $\begin{array}{l}\text { Raskin (2005), Electris et al. (2009), Hunt et al. (2012), } \\
\text { Lombardi et al. (2012), Rogers et al. (2012). }\end{array}$ \\
\hline
\end{tabular}


if?' thinking. The raw data from which this paper draws - the outcomes from two workshops held in 2015 in Birmingham and Bristol - is presented in Hunt and Rogers (2016c), along with reflections on the process. This paper describes the application of the method to reveal a potential engineering intervention and, by applying novel insights from recently completed research (iBUILD, 2018; Leach et al., 2016, 2017, 2018; Rogers, 2018), to support an analysis of: how this intervention might be proposed as a transformative solution to the problem of urban mobility (the 'business case for change'); how it might be shaped to deliver multiple benefits (as a foundation for alternative business models (BMs) to facilitate its implementation); and the implications for changes to the systems of governance to enable the BMs to work successfully. Its efficacy as an essential component of future visioning in 'setting the brief' for civil engineers and other urban professionals is discussed in the light of the findings.

\subsection{A review of aspirational city scenario approaches}

Several authors advocate a process for developing aspirational scenarios consisting of six clearly identifiable steps (Figure 1), each of which should ideally be undertaken drawing from the knowledge of all relevant stakeholder groups (Hunt et al., 2012; Ratcliffe and Sirr, 2003; Rogers et al., 2014). Broad similarities are evident within steps 1-4 and 6, whereas in step 5, where 'scenario logics' are developed, there are subtle differences in the approaches. A brief description of each of these steps, making reference to the considerable body of literature on scenarios, is provided here to set the context in which civil engineers should base their decisions. These six steps form the initial activities of a broader implementation process described by Ratcliffe and Sirr (2003) and developed and tested by Hunt and Rogers (2016a, 2016c), as a result of which the six-step process has been reinterpreted here to focus specifically on the local context since this, crucially, establishes the credibility of the method: it counters the dismissive criticism of 'dreaming up future scenarios ... what if they are wrong?', builds trust among local stakeholders and has a dominant influence on successful implementation.

The initial strategic question, or more properly, set of questions, for a city are defined in step 1. This is essential in informing and shaping an overarching vision, since it provides the fundamental starting point for city decision making (Hunt and Rogers, 2016a). The simplest way to start the process would be to ask a representative city stakeholder group (i.e. a

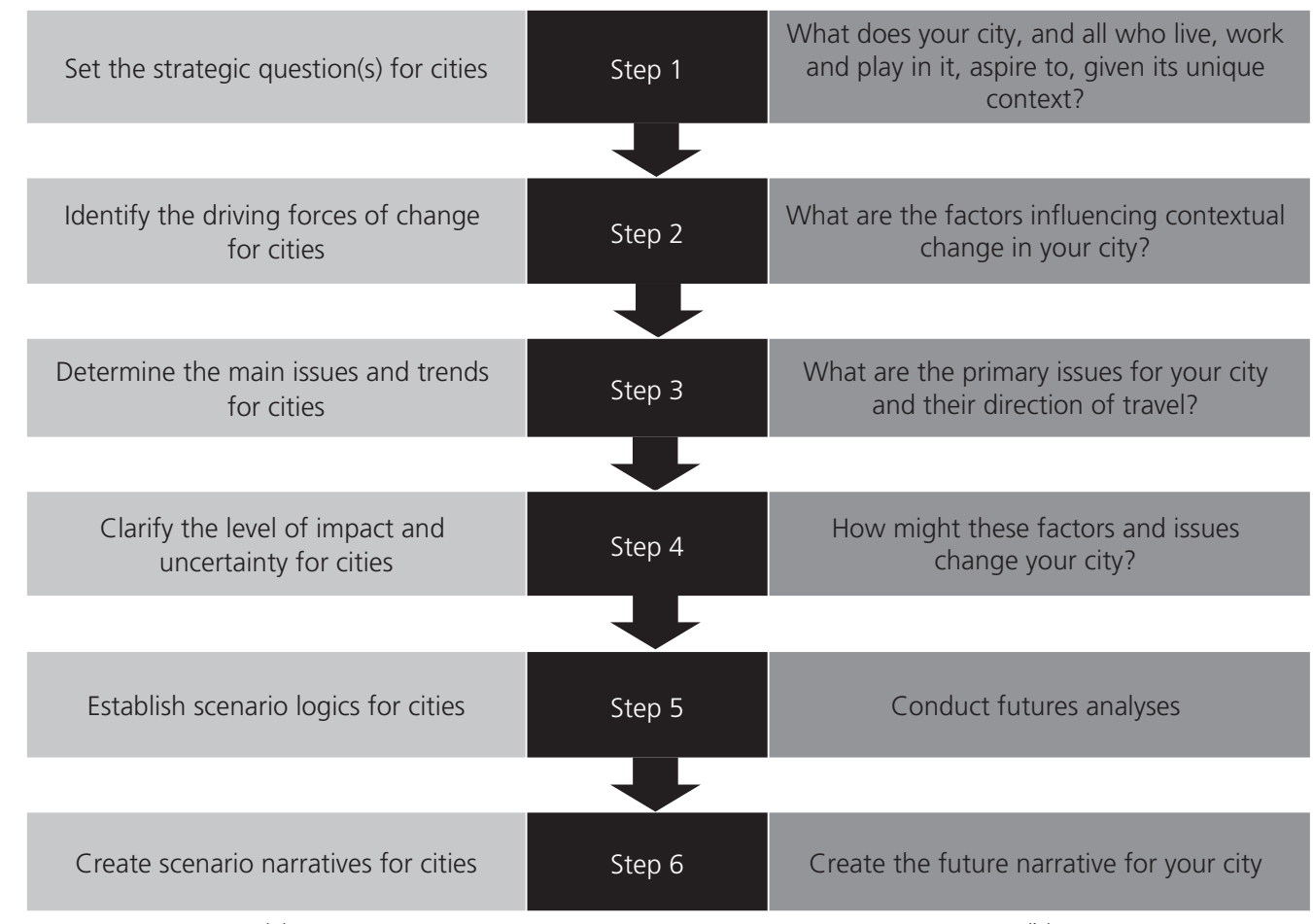

(a)

(b)

Figure 1. A six-step process to developing scenario narratives: (a) a reinterpretation of Ratcliffe and Sirr (2003) general process and (b) by the authors 
combination of citizens and those who govern them, urban practitioners, those representing commercial or business interests, academics and so on) "what do you aspire to achieve in your city?' The answers may well conform to archetypal city visions that exist already (e.g. smart, innovative, liveable, resilient, sustainable, green, carbon neutral, see Cavada et al., 2014). Alternatively, they may accommodate changing aspects of the current environment (Schwartz, 1991) or stem from deeply held beliefs and/or concerns (Hill et al., 2014), or simply reflect preferences that are driven by underlying needs or wants, or Jungian characteristics (Hirsh, 1985; Jung, 1981; Myers and McCaulley, 1985; Quenk, 2000) that describe the personalities of those either being considered or consulted.

In step 2, the key driving forces of change specifically within the city of interest are identified. This is most commonly achieved using a STEEPO analysis (Hunt et al., 2012) or one of its variants (e.g. PESTLE and PESTOR substitutes legal or regulation for organisational)
- S-Societal
- T - Technical
- E-Economic
E - Environmental
P - Political
- O-Organisational

In step 3, these headline drivers of change are refined to include a list of sub-drivers that more clearly identify those aspects that influence the way the city in question is functioning (or could function). Out of necessity these typically draw on two aspects

\section{Events which are 'predetermined' (e.g. Demographics -} city populations will increase, or in some cases, at certain points in time, such as Detroit and Pittsburgh, reduce), for which trend analysis is helpful if applied critically.

- A range of critical 'uncertainties' (e.g. energy availability low carbon city energy will likely not be able to meet demands - or energy prices - city energy costs may be uncertain and volatile), for which trend analysis is found wanting.

In step 4 these sub-drivers are prioritised according to the degree of certainty and degree of impact; those that are deemed to have the highest impact and highest uncertainty are used, at least in some types of future analyses, to establish 'scenario logics' in step 5. Again it is vital that these influences are considered in the specific context of the city under consideration - they will affect different cities in different ways and it is important that the widest possible perspective is adopted, hence the need for a broadly constituted stakeholder group. Such an exercise conducted 10 years ago (WEF, 2008) is revealing in that it exemplifies the range of considerations that need to be embraced and shows how their relevance and importance has persisted and/or changed in the intervening 10 years, some of the key factors being

- Pre-determined factors (from greatest to least importance) - demographics, global wealth distribution, information security, income inequality, environmental self-regulation, corruption.

- Critical uncertainties (likewise from greatest to least importance) - energy innovation and energy prices, global economic growth, non-energy commodity prices, degree of economic co-operation, geographical political power distribution, water availability, global trade balance, climate change, extremism.

While this analysis adopts an economic lens, the categorisation and degree of importance attached to these factors is illuminating. An analysis today might include the following, and most would be likely to be classified as critical uncertainties

- Weather volatility, response to disasters and migration; the rise of extremism and 'terrorism's drift'; geo-political movements in Russia, China and America and external political interference; energy battles - old sources, new sources and international dependencies; food, water and resource scarcity and resource security more generally; the fourth industrial revolution, pervasive social media and fake news; continued repercussions of the 2008 financial crisis and extreme austerity; increasingly ageing demographics in the West and the inverse in developing countries; automation and the changing nature of work; and more immediately Brexit and the stability of the EU.

Step 5 - establishing the 'scenario logistics' for the city in question - is where future analyses are conducted and this can, and ideally should, be achieved using a number of methods (summarised in Table 1): all throw light on the situation, and the process of creating and testing scenarios naturally throws up 'what if?' questions. For example, processes of 'imagineering' to assist urban planning, focusing on visions and values and crystallising lessons from trialling scenarios analysis into guidelines for good practice, are described by Ratcliffe and Krawczyk (2011). The benefits of learning by trialling are reinforced by Inayatullah (2011). Angheloiu et al. (2017), while using morphological analysis and a workshop setting, present an interesting analysis of the influence of values in future analyses and, as will be picked up later, refer to the importance of systems thinking. Ratcliffe and Krawczyk (2011) finish by quoting a truism attributed to Albert Einstein that imagination is more important than knowledge, and in scenario analysis this is most certainly true. While there is value in all scenario approaches, the current authors contend that it is the extreme 
scenarios that provide the greatest utility both in freeing the user's thinking from current constraints and exploring the full extent of the plausibility (and problem) space (Rogers, 2018; Rogers et al., 2012). Interestingly, Bai et al. (2016a), in taking a wider view still by focusing on the Anthropocene, talk of plausible and desirable futures in terms of a new research agenda, while Pollastri et al. (2018) explore futures as conversations aided by visualisations and this leads very well into the final stage, which is once more generally common among the methods. In step 6 , the analyses are synthesised into a narrative for the city that helps to make explicit what needs to be done, and by whom, if a better way forward is to be achieved - delivering benefits, minimising disbenefits and meeting commonly agreed goals such as movement towards sustainability, resilience, liveability and smartness (Rogers, 2018).

\section{Testing the hypothesis of clustering aspirations}

In 2014 the University of Birmingham's Policy Commission on Future Urban Living compiled evidence on thoughts and lessons (of) how we might live, work and play in cities of the future' from a wide range of leading thinkers from the UK and abroad (Rogers et al., 2014). It was found that the process of deconstructing and re-clustering the ideas underpinning this evidence inadvertently prioritises one set above the rest, necessarily raising important questions around a city's priorities and the need to make explicit the consequences of prioritising one city's vision above that of another (Hunt and Rogers, 2016b). As such, three clustered models, each with associated visions and supporting narratives, were developed

- Vision 1. Environment and resources - An environmentally aware world, in which the natural environment is valued for what it provides to cities; therein citizens and resources are marshalled to deliver greater resilience by fostering resource security and the avoidance of resource scarcity.

- Vision 2. People and community - A world in which citizens and communities are mutually supportive and all other aspects of cities are shaped to facilitate this ideal.

- Vision 3. Work and economy - A super-connected world in which the economy, trade and the world of work is prioritised.

By clustering a set of ideas on future urban living, or the collective aspirations for a specific city, around these three visions, which conveniently align closely with the three pillars of sustainability, and then using solely one cluster to set the priorities for a (the) city's development into the far future (the issues in the other two clusters are totally disregarded in terms of priorities), it is possible to establish an extreme vision of the city. Repeating this for the other two clusters in turn creates three extreme visions for the same city.
The hypothesis that emerges from this approach is that an intervention in a city that yields positive outcomes (or reduced negative outcomes) in all three extreme visions is likely to yield great value in terms of city enhancement. It should be noted that it is assumed that technology, policy and organisation (the remaining drivers in STEEPO) align with and support the prioritised cluster in each case (Hunt and Rogers, 2016b). Once this analysis is complete (step 5), it is necessary to create a narrative for the city so that all stakeholders can appreciate the goal, and the direction of travel, and be drawn into delivering it. The narratives created by Hunt and Rogers (2016c) were formulated around the seven key themes identified as important to cities by the Policy Commission on Future Urban Living (Rogers et al., 2014) - see below - but any set of themes, or none, might be used as long as it is appreciated that all themes are interdependent to a greater or lesser degree (GOfS, 2018c) and any attempt at siloed thinking should be abandoned.

- Theme 1 - (NE) Natural environment

- Theme 2 - (NR) Natural resources

- Theme 3 - (T) Transport

- Theme 4 - (RAST) Resilience adaptation and smart technologies

- Theme 5 - (FABM) Financing and alternative BMs

- Theme 6- $(\mathrm{G})$ Governance

- Theme 7 - (CCRRP) Cities and city regions, and the role of planning

For a full set of narratives, see Hunt and Rogers (2016b).

\section{Case studies}

\subsection{Application of the aspirational futures methodology}

The aspirational vision clustering approach described above was trialled in Birmingham and Bristol using day-long workshops with a total of 64 stakeholders to establish its efficacy (Hunt and Rogers, 2016b). The three-stage methodology is outlined in Figure 2.

Stage 1. Prior to the workshop, delegates were asked to think about their far-future ( $>50$ years hence) aspirations for their city unconstrained by any current context. To facilitate this thought process, the delegates were provided with copies of ARUP's Cities Alive: 100 issues shaping future cities (Arup, 2019) and synopses of existing aspirations for the future of their city - aspirations (or city visions) that were published within the last 10 years - see Figures 3 and 4.

Stage 2. On the day of the workshop, delegates were asked to write their aspirations for their city (visible from $3 \mathrm{~m}$ away to enable them all to be read) on large colour-coded 'post it' 


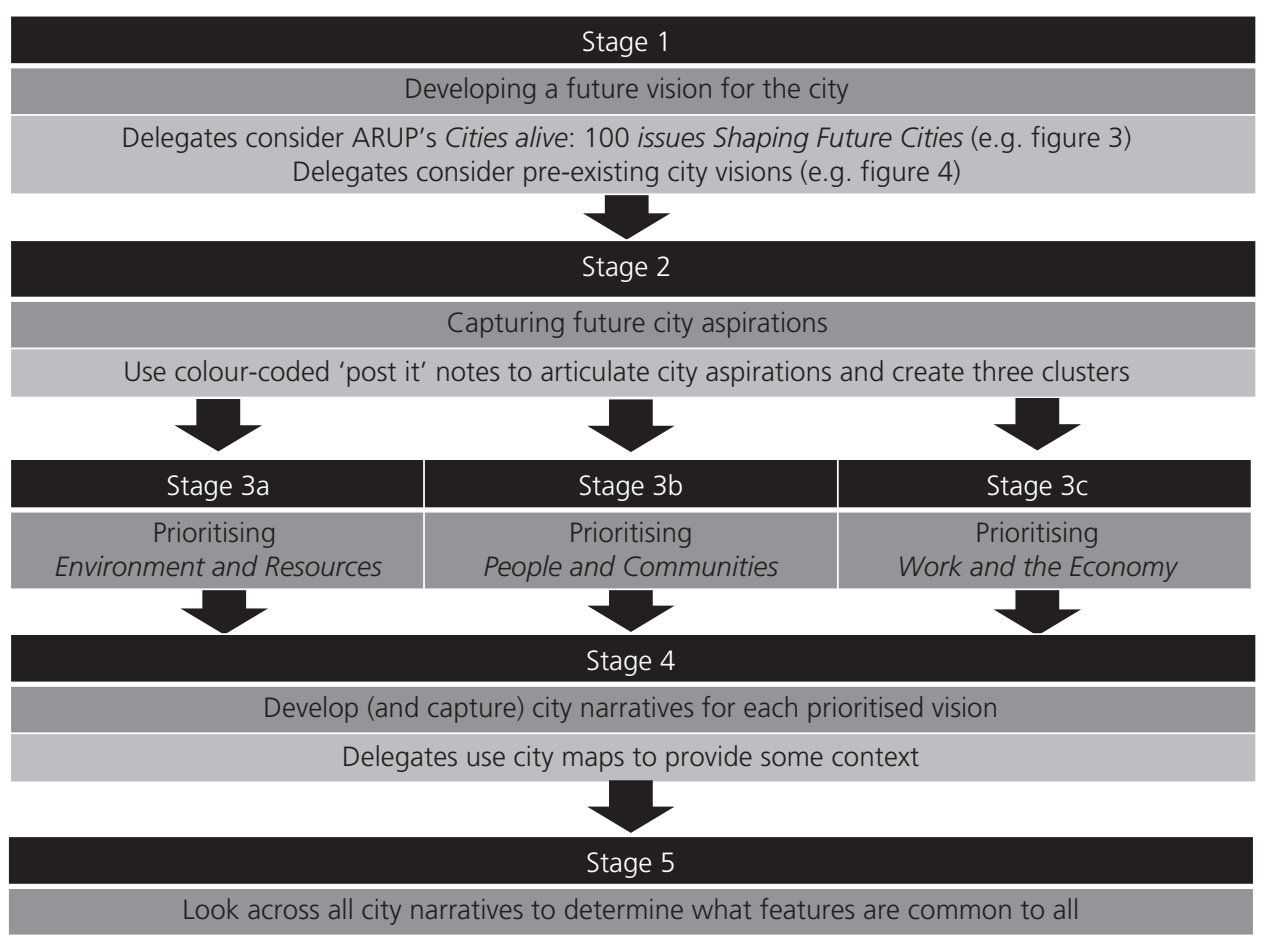

Figure 2. Methodological process followed for developing 'prioritised' aspirational city visions

notes. These were clustered under one of the three visions, the clustering was refined and added to (where omissions were identified), and ultimately the clusters were agreed to by all.

Stage 3. Delegates were subsequently provided with Google maps of the city and asked to consider what their city might look like, and how it would operate, if the aspirations solely from one cluster were adopted as the priorities for the city's development over the next 50 years. This exercise was repeated for each of the clusters in turn, and once all three had been covered and three sets of maps were made available for view, a plenary discussion took place. This discussion was captured and, when read in conjunction with the evidence collected in stages 1 and 2, powerful extreme future narratives for the city were created (Hunt and Rogers, 2016c). Features that were common to the three extreme narratives were identified as likely worthwhile investments, features that provided a move towards commonly agreed goals (such as sustainability, resilience and/or liveability) were debated, and reflections on how the process aided thinking about the future were aired. All of this was fed into a single narrative for the city's future.

\subsection{An exemplary aspirational city intervention - green infrastructure corridors}

While it is not possible to present all the aspirations, or the complete narrative sets - these can be found in Hunt and

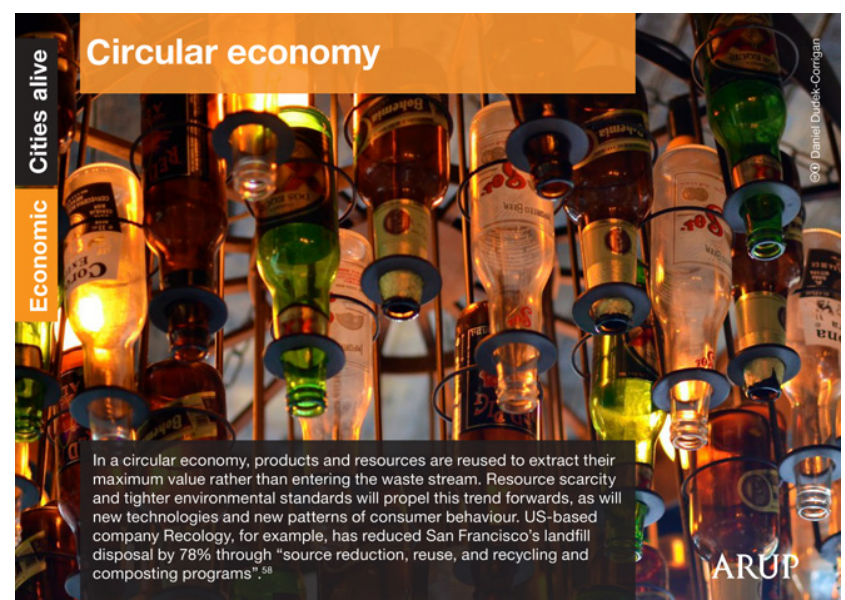

Figure 3. Example card from Cities Alive: 100 Issues Shaping Future Cities (Arup, 2019)

Rogers (2016c) - an example outcome of potentially profound importance to city planners and urban professionals in general, and civil engineers specifically, deriving from recent research on urban green spaces and the ecological ecosystem services that they provide (Sadler et al., 2018), is described below. The important point behind this demonstration of the 


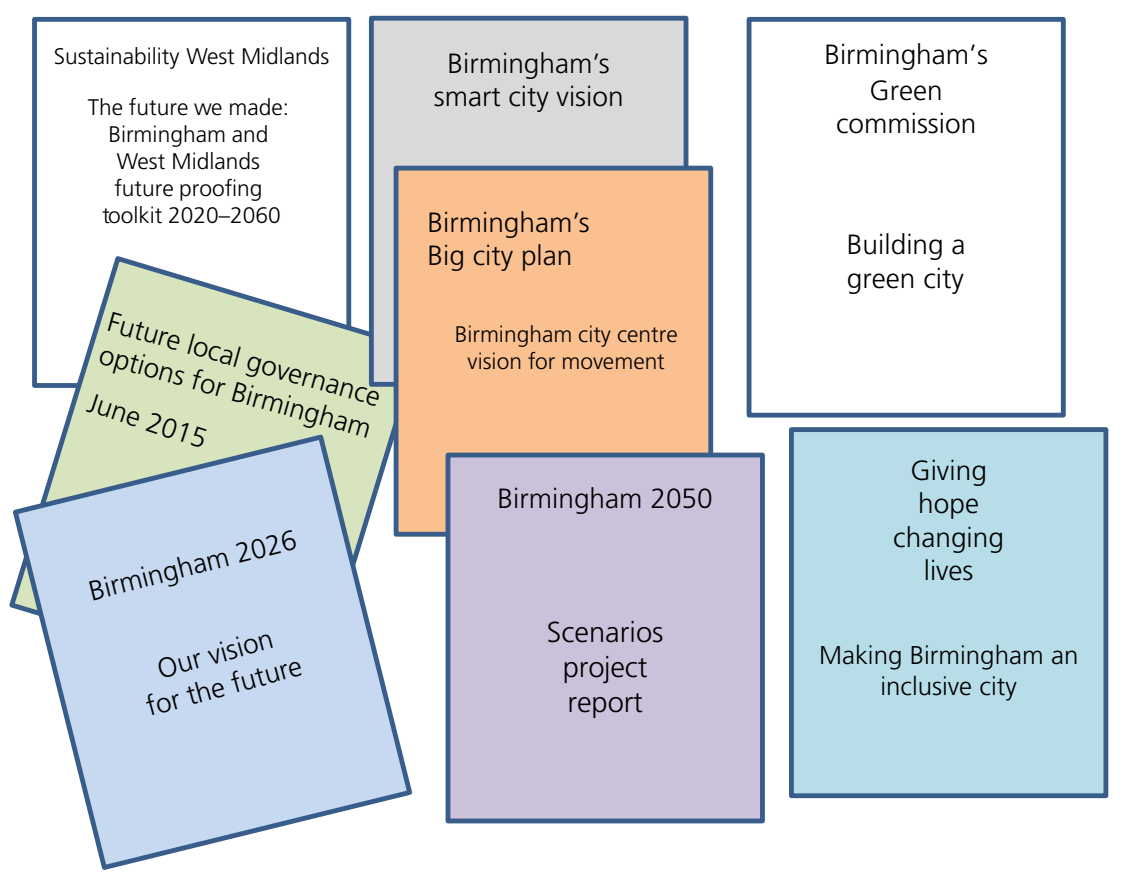

Figure 4. Examples of visions collected for the Birmingham workshop

method is that that individual (or multiple) intervention(s) might be proposed within city planning circles to address a particular problem, and yet if it (they) fail(s) to meet the longer-term aspirations of the city then a potential opportunity is lost and the value is potentially diminished. Indeed, alignment of any city intervention with the city's aspirations should form a vital part of the assessment of its likely long-term value, and therefore inform the business case for, and the alternative BMs that enable, its implementation (Bryson et al., 2018). Equally the intervention, and its associated BM, needs to be analysed in terms of the full suite of problems that a city faces (a robust methodology for the diagnostics of which is given by Leach et al., 2019) - does it help in addressing several of the city's problems? - and tested for its resilience (Rogers, 2018), and this is also exemplified below.

The intervention being trialled, using the outcomes from both workshops, is the introduction of green infrastructure corridors (GICs). It should be noted that any urban systems intervention could be trialled using the raw data contained in Hunt and Rogers (2016c), and that the workshops did not point specifically to the intervention being trialled here. The aspirations that support such an intervention in Bristol and Birmingham, selected from the complete set of aspirations reported in Hunt and Rogers (2016c), are shown in Tables 2 and 3, respectively, from which it can be seen that the provision of GICs positively supports the delivery of 34 (out of the 108 collected) aspirations arising from the Bristol workshop and 33 (out of 89) aspirations from the Birmingham workshop.

\subsection{Comparing the Birmingham and Bristol aspirations}

When comparing the synthesised, single visions for each of the cities, unsurprisingly broad similarities can be found in the city aspirations supporting the visions. Both talk about a city that is walkable and connected (and interconnected), with a comprehensive cycle network, increased number of cyclists and a reliable 'no-polluting' public transport system. The aspirations, and visions, describe car numbers having been reduced, particularly in city centres where 'car-free' has been adopted. Both cities value and embrace nature (referring frequently to 'green'), embedding it within a natural economy where there is increased awareness of and protection for a nature-rich city (e.g. significant increases in tree cover) where empowered citizens live. Moreover, both cities aspire to live within their means (and resources), be cleaner and more efficient with 'smart' communities that are far more self-sufficient concerning waste, energy and food. Therein, a larger range of small businesses do far more things locally sharing resources happens readily and is backed by a political will that takes long-term views and decisions.

The danger here is that this becomes an unconstrained wish list. However, if these aspirations - which de facto suggest that they 


\section{Bristol's environmental aspirations}

(T) Walking or cycling always first choice

(T) Welcoming spaces - walkable bike-able

(T) Public transport; non-polluting interconnected

(NE) We never (again) talk of 'exploiting nature'

(CCRRP) Recreational, natural spaces within walking/accessibility reach of all homes

(CCRRP) Urban spaces ( $\rightarrow$ Streets, houses, neighbourhoods) that actively support health

(RAST) City systems connected, automated and responsive to local needs/priorities

(NE) A city that leads the way in environmental and human innovation

Bristol's social aspirations

(CCRRP) I don't need to wait to cross a road as they are there for people

(G) A fair and equal society without poverty

(CCRRP) Strong sense of pride/ownership by communities of their neighbourhoods

People share, connect, support each other in local informal and formal networks

Healthy lifestyles in all parts of city

(T) Reduced need to travel

(T) Everything I need to access is easy walk + cycle

Bristol's economic aspirations

(RAST) Connected (e.g. fast Internet)

(RAST) A convergent resilient industrial centre

(FABM) Local partnerships blur lines between the

public/private and the third sector

(G, FABM) Circular economy based on local manufacturing
(T) Fewer cars in the city centre (parked + moving)

(NE) We know we are nature (+ we deplore exploitation)

(NE) Air clear as in the countryside

(NR) A city that lives within its means (resources)

(G) Local, small-scale services make city cleaner, more efficient and accessible

(NE) Increased tree cover, biodiversity and nature-based solutions in urban area improve the quality of life for all

(NE) Green space providing clean air, water, biodiversity and somewhere for people to enjoy

(G) There is no need for projects called 'age-friendly city', 'nature-friendly city', 'city of sanctuary' and so on

(T, CCRRP) Accessible to all people

(CCRRP) A region of local urban centres sharing a core centre + services

(CCRRP, T) Healthy, safe, fun ways for people to move around the city

Children out and about independently

(G) Localism

(T) No cars

(T) Transport (improved)

(T) No cars (or at least no cars singly owned, only shared), many more bikes

(T) A city with no internal mobility barriers do, or could, accord with citizen attitudes and behaviours once they are made aware of the benefits - could be met while interventions are being implemented to deal with problems that are evident today (e.g. providing enhanced connectivity between suburbs in a city to facilitate new housing developments), then the likely success of the intervention into the long-term future is greater, the investment case is de-risked and the value (whether economic, social, environmental and/or political) is increased.

\subsection{Assessing the resilience and investment proposition of GICs}

Taking the case of GICs forward, while they have been shown to align well with both cities' aspirations, and therefore would likely prove a good investment, there is no specific analysis of the benefits that GICs would bring to the city - no specific points of value that could be included in an investment case to set against the cost of implementing them (Bryson et al., 2018). Three methodologies that uniquely combine to address this omission are described by Rogers (2018). Although all three should ultimately be combined in a robust decisionmaking process, it is helpful to consider them as three distinct strands of activity. The first is the Liveable Cities methodology (Leach et al., 2018), a process in which the desired future characteristics of the place in question are established (combining liveability principles with sustainability and resilience); an engineering intervention is conceived to move the place towards the desired future; the multiple benefits that might be realised from this engineering intervention are made explicit; and the current context is explored to examine whether each benefit is likely to be realised if the intervention were implemented today. As a result of the new aspirational futures methodology introduced in this paper, the desired future characteristics can, and should, now include alignment with the city's and citizens' aspirations. The third methodology creates alternative BMs that capture combinations of the benefits thus identified, alongside the other consequences of making the system intervention, and balances them against the alternative forms of investment that might be used to bring it about (see Bryson et al., 2018). Importantly, an understanding of the system in which the intervention is being proposed and its interdependencies with all other urban systems on which the intervention impacts (either positively or negatively) is 


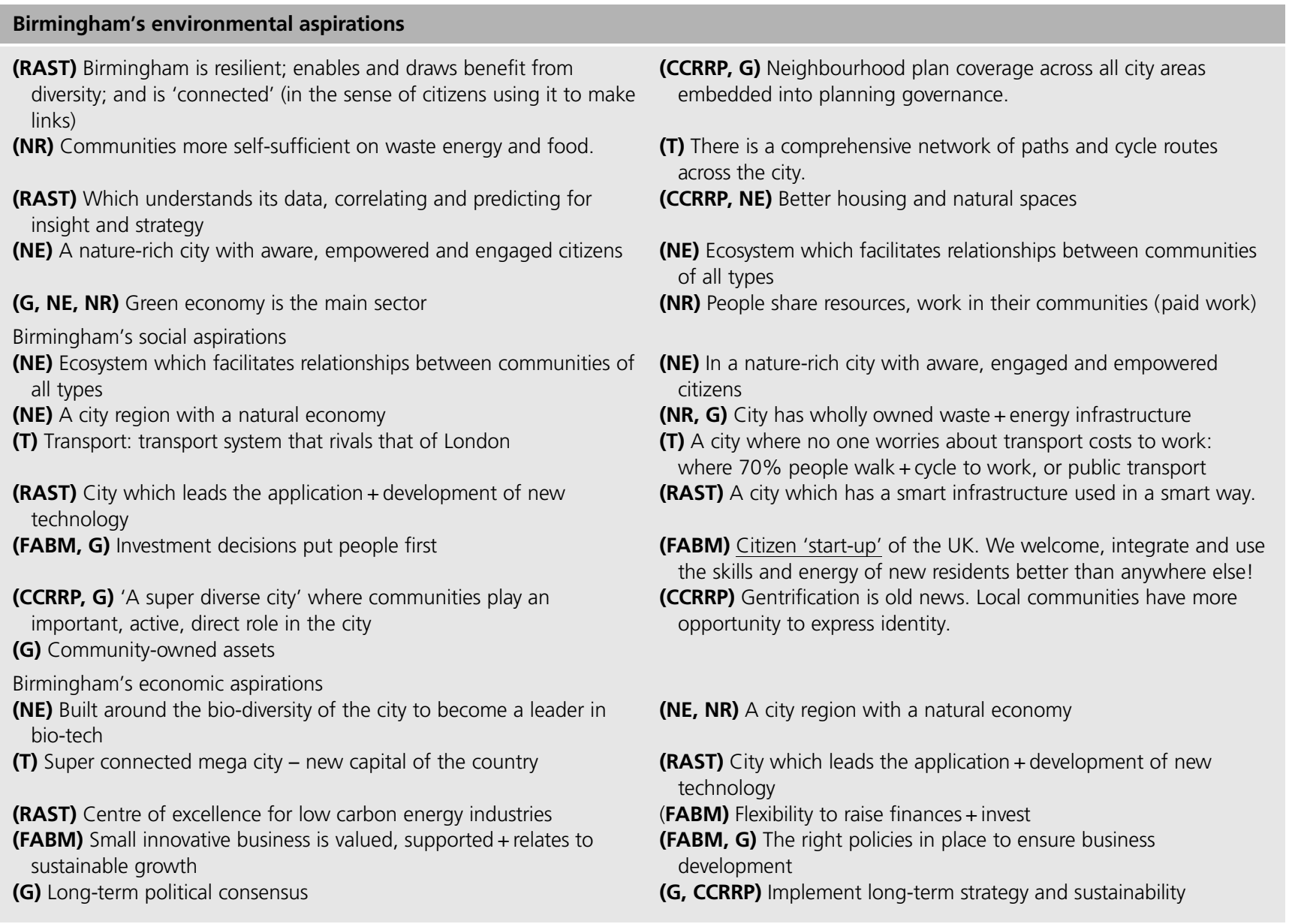

essential if the BMs are to be comprehensive (Bouch and Rogers, 2017; Bouch et al., 2018). This fact is reinforced by others who have engaged in futures analyses, such as Bai et al. (2016b), who point to the often unrecognised opportunities it presents 'to maximise co-benefits and synergies (and) guide management of inevitable trade-offs' in bringing about more sustainable cities (see Lombardi et al., 2011).

When applied to the GIC example, it not only assesses whether an intervention is positive in terms of sustainability and resilience - core considerations of any proposed project, noting that economic vitality occupies one pillar of sustainability and necessarily features in resilience - and it meets the city's and citizens' aspirations (the process described above), but establishes whether the intervention is likely to be successful by specifically identifying all of the benefits arising from the intervention - termed GICs' intended benefits (IBs) - and whether they are likely to be realised now and in the future in the (geographical, political) context in which the intervention is to be implemented. (This latter point is important, since what might succeed in one city might fail in another.) Put another way, the IBs represent all forms of value that GICs might realise (social, environmental, direct economic, indirect economic, cultural, political etc.) and all adverse consequences that GICs might minimise (social harm, environmental harm etc.). For any one benefit to be delivered, the conditions necessary for the benefit to be delivered - the necessary conditions (NCs) - are identified, and, in turn, these can then be tested for compliance with the city's aspirations. An example of this thinking applied to the implementation of a GIC as though it were conceived as a solution to a current problem in Bristol is given in Figure 5, drawing in Table 2. Unsurprisingly, it shows that GICs are likely to succeed for the same reasons as described earlier, but using a reverse approach to test it.

Rogers (2018) presents two further methodologies to understand whether an intervention - the provision of GICs - is likely to prove successful. The above arguments are predicated 


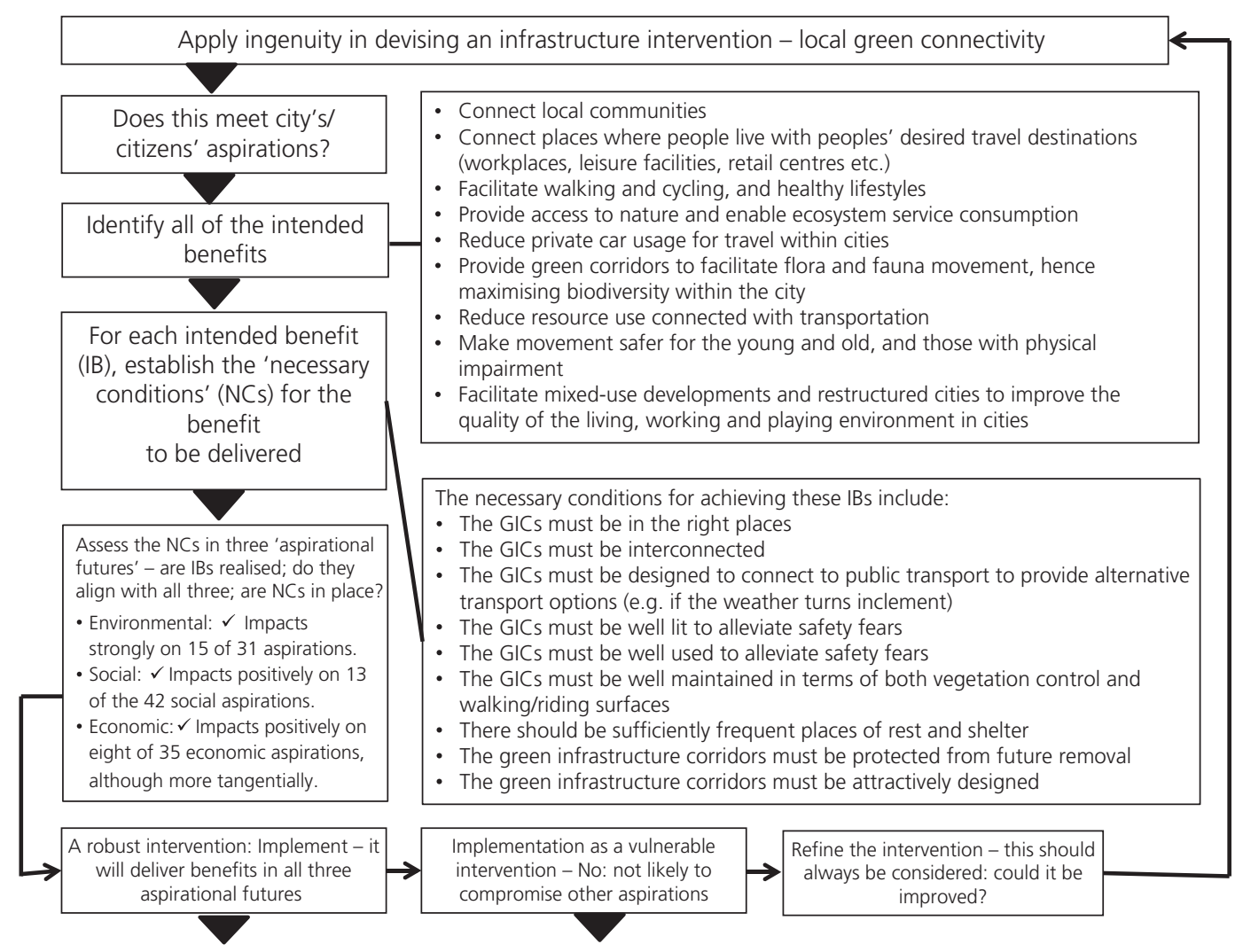

Figure 5. Example assessment of GICs, with the NCs amalgamated to address all of the IBs

on whether an intervention would work in a particular place now and in the future assuming the NCs remain in place - that is, that the context does not change. The second methodology assesses whether the intervention is resilient to contextual change - whether the intervention is likely to continue to deliver its IBs - using the designing resilient cities method, which derived from the Urban Futures project (Lombardi et al., 2012; Rogers et al., 2012). The third methodology establishes whether the business case for the intervention's implementation, and the BMs needed to facilitate it, are likely to be robust (Bryson et al., 2018, augmented by emerging research findings from iBUILD; see Bouch et al., 2018; Dawson et al., 2014; iBUILD, 2018). These are applied to the case of the provision of GICs in Bristol in Table 4 and Figure 6 .

The designing resilient cities method analyses the intervention in its current context to determine whether it would be successful today (the NCs are in place today) and then in four extreme futures (see Table 1). If the NCs exist today and in all futures, the intervention can be considered robust (i.e. not 'vulnerable' to contextual change) and can be implemented with confidence that it will continue to deliver its benefits into the far future (i.e. the investment has been de-risked). If, however, some NCs are lacking in one or more extreme future, the intervention's vulnerabilities are made explicit and either implementation can occur in the knowledge that it might be vulnerable to contextual change (and hence might fail to deliver all of its benefits) or the intervention can be redesigned and retested. Once the design of the intervention - here the GICs - is finalised and the business case has been established, alternative BMs can be explored to enable implementation, noting that if no suitable model can be found, the intervention itself might need further iteration (Figure 6).

\section{Discussion}

In all work associated with future thinking - whether considering how urban intervention can itself contribute directly to sustainability or indirectly in support of wider national and global agendas (e.g. the UN Sustainable Development Goals; UN, 2015), resilience (e.g. directly or indirectly by contributing to climate change mitigation), liveability or smartness - the advancement of an individual's thinking by simply engaging in the process is widely acknowledged as one of the major benefits. This proved to be the case in the Birmingham and 
Intervention: The creation of interconnected GICs throughout the city for walking and cycling, linking local communities and the suburbs to the city centre.

Aspirational scenarios: The intervention positively supports the delivery of 34 of the 108 collected aspirations arising from the Bristol Aspirational Futures Workshop (see Table 2 and Figure 5; Hunt and Rogers, 2016c).

Extreme-yet-plausible scenarios: The intervention would be vulnerable if the world moved towards an extreme market forces scenario, in which social and environmental considerations are largely discounted in favour of economic considerations, and therefore, any evidence of economic benefits of implementing the intervention should be a priority. The intervention would be uncertain for 'the haves' in a fortress world scenario, but would be essential for the 'have-nots' and the intervention would therefore deliver most of its IBs. The intervention would be embraced by all in the new sustainability paradigm and would be certain to work well, while it is also likely to prove effective in the policy reform scenario due to its strong social credentials. The balanced portfolio of multiple benefits across all 'three pillars' of sustainability is likely to make the intervention successful, and importantly, to be politically acceptable.

Business model: The intervention would require considerable investment to create the ultimate outcome - connected GICs throughout the city synthesised with public transport - yet it is an intervention that could be undertaken progressively with progressive benefit realisation. Neither is it an 'all or nothing' solution to the problem of enhancing connectivity in cities - experimentation is possible: it could be trialled in certain obvious locations. The value proposition is very strong as a result of the many evidently tangible benefits, as well as many less tangible benefits - these include citizen health and well-being, reduction of the consumption of both renewable and non-renewable resources, cleaner air, enhanced biodiversity, reduced traffic congestion and 'permission' for politicians to restrict private car usage. In fact, the list of benefits is extensive and leads to very many discrete sources of social, environmental, economic, political and cultural value, which can be identified and included in the 'business model; the City LIFE ${ }_{1}$ methodology, developed by the Liveable Cities programme, contains 346 performance parameters that cover the entirety of 'liveable city performance' and provide the basis for judging where the potential sources of value arise from an intervention (Leach et al., 2016, 2017), as do the many sustainability assessment frameworks from which it is derived. The value, which will increase progressively over the timeline of implementation and operation of the intervention, is then judged against the investment, which likewise will be progressively applied and will consist of economic, social (e.g. local maintenance) and environmental capital (e.g. ecological ecosystem service provision to the city and its citizens) using some form of framework (e.g. iBUILD, 2018). Finally, all the other systems of governance, ranging from the softer aspects of encouraging change in citizen attitudes, societal norms and citizen behaviours through to the harder aspects such as legislation (banning cars from parts of the city) and taxation (road congestion charging) need to be engineered - creating further enabling conditions to support the NCs once the BM has been formulated would be part of the refinement process, and iteration throughout these methodologies will yield the most robustly designed intervention.

Refinement: GICs should be synthesised with public transport, allowing 'hop-on, hop-off', with shelters sited at these locations of intersection and at intermediate points to ensure adequate frequency. The design of the GICs should be co-created between the local communities and the relevant urban professionals to ensure that they are sited appropriately to local needs, provide the services that are required (walking, cycling, disabled access, pram access, etc.), and to engender co-ownership of the intervention, exploring possibilities for local communities engaging in their maintenance (litter picking, pruning, leaf clearing, etc.) and supporting the 'BM'. Co-design with citizens would also make this politically more desirable since it reduces the 'political risk'.

Bristol workshops. Once the exercise had been completed in both cities, a plenary session to reflect on the process was held to allow participants to raise concerns, ask questions and comment generally on the day. The primary learning outcomes identified from this discussion included

- The aspirational future cities methodology was praised for the way it brought into sharp focus synergies between all of the elements of the city's and citizens' visions.

- The process of prioritising clusters and creating narratives was thought to be both necessary and helpful in introducing the consequences of downplaying, and trading off, key elements of a city vision.

- The most important benefit to those who took part was that the process of applying this methodological approach allowed them to think 'outside the box' - free from having to consider the constraints applied within their everyday roles.

- While the use of maps certainly helped set the context and initiated conversations, the disadvantage was that delegates might ground themselves in the present. The use of Google satellite maps, which were adopted for the Bristol workshop, proved helpful. The use of additional, more detailed maps (i.e. those that included age distribution, fuel poverty, wealth distribution, access to green space and so on) was trialled in Birmingham, but it quickly became apparent that they constrained thinking by focusing minds on the present challenges and how to address them.

A Google satellite map therefore allows delegates to have some, but not too much, context in which to position their city aspirations.

- The question arose as to what scale is appropriate to think about the implementation of visions for cities. When thinking about Environment and Resources, delegates tended to look at this as both a strategic and local issue, relevant to the city scale and beyond. When considering the visions around social and economic issues, however, the discussions started at the city scale, but then tended to move to a neighbourhood scale. This was particularly evident in the case of People and Community. Users of the method should attempt to consider multi-scaler and multi-temporal perspectives. 


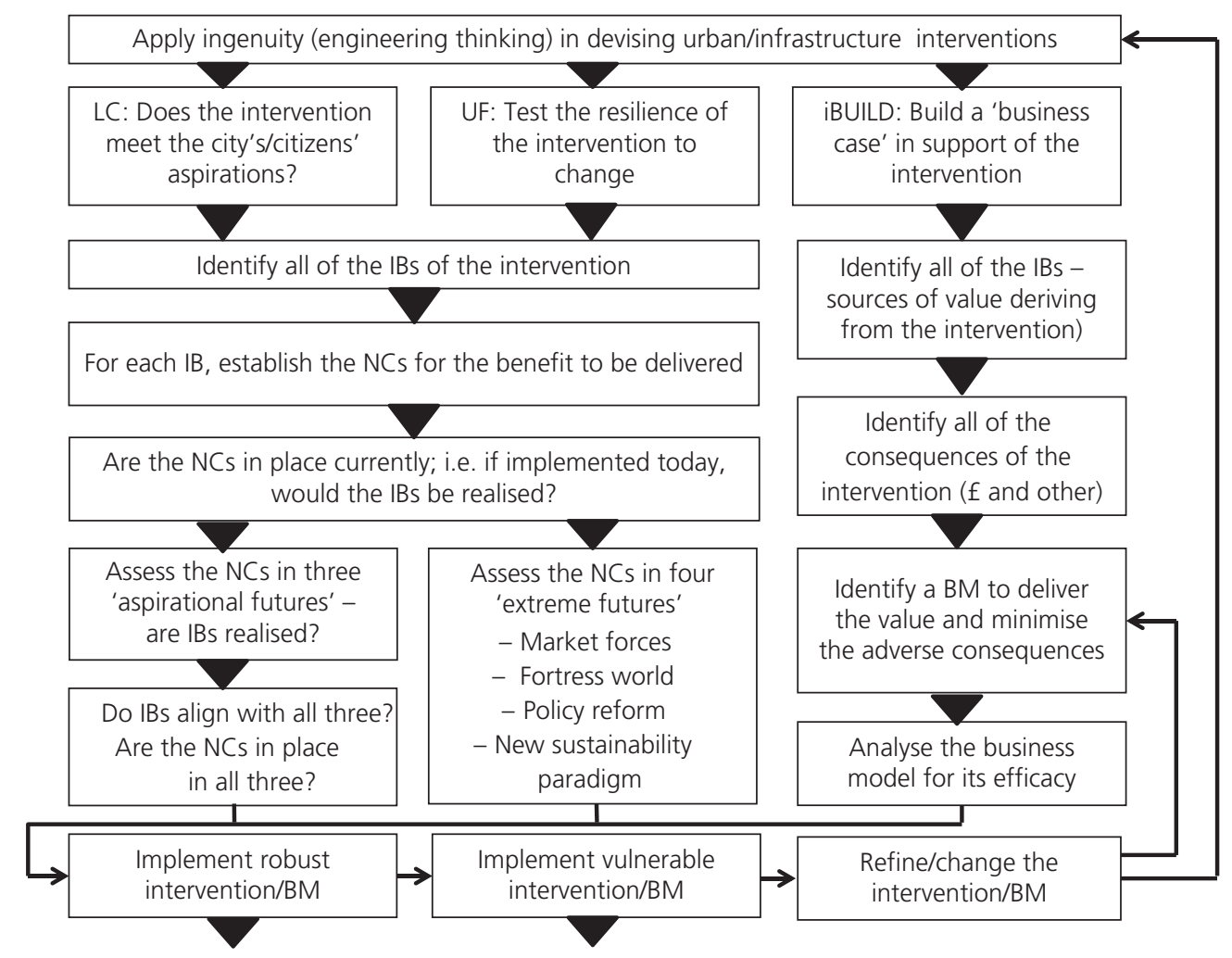

Figure 6. Synthesis of methodologies for assessing the robustness of GICs implemented in Bristol for resilience, liveability and investment proposition

No matter how willing the delegates were to ignore the previous visions when concentrating on a new set of aspirations, it was evident that previous discussions did tend to influence the new ones to a small degree. For this reason, it is suggested that Environment and Resources be addressed first as the environment necessarily provides a fixed boundary - one that needs protecting - and this would sensibly be followed by People and Community, with Work and Economy coming last. This sequence follows the nested concept of sustainability in which concentric circles show economy inside society inside environment, while adopting it removes the economic constraints from being considered until the end of the process, and these can be specifically dealt with in the final set of discussions.

The most important learning point of the whole exercise, however, is that creating an extreme vision - one in which one focused set of priorities shape policies and practices and is used to establish a future world in which only those ideas matter - allows users of the method not only to think 'what if?', but also 'why not?'. If it is possible to envision a world in which, for example, only considerations of the environment and resources matter, and explore how people might operate in that world, and understand what their values might be, and what would need to be done to get there, then it becomes an alternative reality and something that could be achievable if only ...'. This is not a future world that can be envisioned, or reached, if all of the aspirations for a city were considered at once - workshop delegates would compromise, start to trade one thing off with another, become overwhelmed by the multiplicity of demands that need to be met, and become incremental in movements towards change.

The Foresight Future of Cities project challenged cities to create their own visions for their own cities (GOfS, 2017b; Van der Heijden, 2005), and the University of Birmingham Policy Commission on Future Urban Living (Rogers et al., 2014) de facto established a set of general city aspirations, but without a process such as that described herein, the very many challenges and priorities that would emerge from the morass of complex interrelated issues that necessarily exist in 'cities made up of people' would lead to confusion, bias (whether intended or not) and a total lack of transparency in decision making. It is for this reason that the aspirational futures method is truly transformative, both for the people taking part in the process - delegates 
have uniformly stated that it has changed the way they think about the approach to their work - and for the cities and citizens for which the interventions are conceived, designed and implemented. Moreover, and crucially, it balances the top-down approaches that are brought to the topic by professional urbanists, drawing on their disciplinary training, skills and expertise and abilities to work professionally across disciplines, with a bottom-up approach, since the workshop delegates are required to bring the views of citizens and communities to the conversations.

The method undoubtedly takes significant time and effort - half a day or longer plus some initial preparation time for the delegates, and many days for those organising and capturing the outcomes from a workshop - and this effort needs to be justified in terms of both cost and time. It also requires strong local leadership to make it happen. There is much political interest in cities locally, nationally and internationally, while those governing and providing services to cities commonly experience severe operational difficulties due to a lack of resources (both funding and staff capability and capacity). Indeed, in some cases, the economic situation is so extreme that city councils cannot continue to offer services in the way that they have done in the past - they need to adopt novel, transformative solutions, which, in turn, need to be accepted by their citizens. The political will to initiate an aspirational futures analysis should therefore exist. Indeed this was the experience of the Foresight Future of Cities project, with cities welcoming city visions workshops (some 20 were held). Moreover, those who govern cities frequently express the desire to take citizens' wishes into account when introducing changes to the cities landscape or systems, but have no realistic or robust means of establishing them and thus make decisions on the basis of what is thought to be best in the hope that citizen behaviours will change to make the change work. The aspirational futures methodology, uniquely, provides this capability in a practical manner.

Taking a devil's advocate viewpoint, the methodology would need to stand up to misuse or manipulation. If it involves people with their own world views (Taylor et al., 2017) and agendas, then an individual would naturally be able to advance this agenda during a workshop. However, with sufficient people attending the workshop, reviewing and agreeing on the clustered aspirations, and reviewing and agreeing on the potential interventions and their likely outcomes, the potential for one view to dominate is greatly diminished; moreover, the workshop facilitators would not allow it. One core feature of the methodology is that, once it has revealed potential socially desirable interventions, it positively enables final implementation by helping to bring into alignment all of the forms of governance essential to successful delivery. These range from the formal (legislation, taxation, regulation, codes and standards etc.) to the informal (individual and societal attitudes and behaviours, societal norms). The local government can use the formal levers of governance to force or incentivise citizen behaviours, yet if an intervention has been designed with citizen aspirations in mind then invoking these formal governance mechanisms, with the associated uncertainty of their success, would be unnecessary. This moves the situation closer to the much aspired to, although rarely achieved, process of urban system co-creation. The final aspect of the design of any urban intervention is to 'engineer all of the forms of governance' to make the intervention a success (Rogers, 2018); the aspirational futures methodology achieves much of this as a result of its design.

\section{Conclusions}

Civil engineering requires civil society - people - to be put at the heart of its activities, and this implicitly underpins everything that civil engineers do. Since urban environments are engineered collaboratively with all urban professionals, this core imperative extends wider. There is, however, an increasing recognition that this perspective is somewhat buried in the routine activities that civil engineers and other urban professionals engage in - there is a separation between professional activities and the people who ultimately benefit. This might be described in terms of providing civil society with what it needs rather than looking more closely at what it wants - and if it were possible to understand and satisfy the wants alongside the needs, then interventions in cities and city systems are likely to be more successful. Tools are therefore needed to help achieve this.

Building on considerable research, knowledge and understanding of sustainability and resilience, Liveable Cities joined with the Foresight Future of Cities project to explore how better to draw in people, society and social perspectives to the way that cities of the future are designed and operated, and hence formulate policies and make decisions that take cognisance of this view while looking towards the far future. In short, this means adopting liveability as one of the goals of civil engineering work and a recognition that there is a need to engineer all of the forms of governance that surround engineering interventions - that is, embracing social attitudes, societal norms and user behaviours alongside the more formal systems of standards, rules, regulations and laws.

The method described herein uniquely facilitates all of this by creating three extreme, far-future aspirational scenarios for a particular city - scenario visions created solely on prioritising policies and practices related to Environment and Resources, or People and Community, or Work and Economy, starting now and shaping the city for the next 50 years. Trialled in Birmingham and Bristol - to provide the raw data sets published in conjunction with the Foresight Future of Cities project - the feedback from both workshops was 
refreshing: delegates 'bought into' the three-pronged approach to creating far future visions, and appreciated how each aspirational future vision contributed to and combined into a single, coherent vision. Crucially, this synthesised vision for an 'aspirational city' would not have been reached by considering all of the issues at once. There was consensus that the process of deconstructing and clustering the ideas, and prioritising one set above the rest, sheds a new light on the issues at hand and would immediately influence the delegates' day-to-day work. Indeed, one delegate stated that the richness of the process resulted in uncovering new questions about the city.

A core tenet of the way in which nations, and cities, are governed - democracy - demands that those who wish to govern understand well the needs and wants of society and put forward plans to meet these needs and wants. However, with myriad issues surrounding all these needs and wants, the process inevitably leads to a small number of manifestos each containing multiple potential solutions to problems, policies and promises. The process of electing people to govern on the basis of these manifestos leads to disputes over precisely what it is that the voters want - an issue that is reflected throughout contemporary discourses in relation to thinking on major matters.

This confusion results from the enormous complexity of the interdependent challenges facing cities, and their causes, and therefore it is unsurprising that this complexity is not well dealt with. The extreme aspirational futures methodology described here uniquely provides a way of understanding how interventions might deliver multiple benefits, satisfying both needs and wants, therefore bringing a degree of clarity to urban decision making. Used alongside the other tools developed by Liveable Cities and similar research, there is an opportunity to de-risk the decisions taken today that aim to deliver more sustainable, resilient and liveable cities of the future. The aspirational futures methodology therefore truly facilitates a transformation of the engineering of cities - it provides the final missing link between provisioning for and co-creating with society to deliver successful urban systems and urban landscapes that meet all of their goals.

\section{Acknowledgements}

The authors gratefully acknowledge the financial support of the Engineering and Physical Sciences Research Council under grant numbers GR/S20482, EP/C513177 and EP/E021603 (Birmingham Eastside Regeneration - Sustainable Urban Redevelopment), EP/F007426 (Urban Futures), EP/J017698 (Liveable Cities), EP/K012398 (iBUILD) and EP/P002021 (Urban Living Birmingham), and the inspiration, knowledge and wisdom passed on by all those with whom they have worked in association with these research grants. The first author also gratefully acknowledges the members of the
Foresight Future of Cities project, with whom many profoundly informative debates have been had.

\section{REFERENCES}

Angheloiu C, Chaudhuri G and Sheldrick L (2017) Future tense: alternative futures as a design method for sustainability transitions. The Design Journal 20(S1): S3213-S3225.

Arup (2019) Cities Alive: 100 issues shaping future cities. Arup, London, UK. See https://www.arup.com/perspectives/publications/ research/section/cities-alive-100-issues-shaping-future-cities (accessed 20/05/2019).

Bai X, van der Leeuw S, O'Brien K et al. (2016a) Plausible and desirable futures in the Anthropocene: a new research agenda. Global Environmental Change 39: 351-362.

Bai X, Surveyer A, Elmqvist Tet al. (2016b) Defining and advancing a systems approach for sustainable cities. Current Opinion in Environmental Sustainability 23: 69-78.

Bezold C (2009a) Aspirational futures. Journal of Futures Studies 13(4): 81-90.

Bezold C (2009b) Jim Dator's alternative futures and the path to IAF's aspirational futures. Journal of Futures Studies 14(2): $123-134$.

Bezold C (2010) Lessons from using scenarios for strategic foresight. Technological Forecasting and Social Change 77(9): 1513-1518.

Bouch CJ and Rogers CDF (2017) A systems thinking approach to the development of alternative infrastructure business models. Proceedings of the International Symposium for Next Generation Infrastructure (ISNGI 2017), London, UK, pp. 55-63.

Bouch CJ, Rogers CDF, Powell M and Horsfall D (2018) Developing alternative business models for smart infrastructure. Proceedings of the Institution of Civil Engineers - Smart Infrastructure and Construction 171(2): 77-87, https://doi.org/10.1680/jsmic.18.00003.

Boyko CT, Gaterell MR, Barber ARG et al. (2012) Benchmarking sustainability in cities: the role of indicators and future scenarios. Global Environmental Change 22(1): 245-254.

Bryson JR, Mulhall RA, Song M et al. (2018) Alternative-substitute business models and the provision of local infrastructure: alterity as a solution to financialization and public-sector failure. Geoforum 95: 25-34.

Cavada M, Hunt DVL and Rogers CDF (2014) Smart cities: contradicting definitions and unclear measures. Proceedings of the 4th World Sustainability Forum; Sciforum Electronic Conferences Series. See https://sciforum.net/paper/view/2454 (accessed 20/04/2019).

Curry A, Hodgson A, Kelnar R and Wilson A (2005) Intelligent Infrastructure Futures: The Scenarios - Towards 2050. Report commissioned for the Foresight Programme of The Office of Science and Technology, London, UK.

Dator JA (2002) Advancing Futures: Futures Studies in Higher Education. Praeger, Westport, CT, USA.

Dawson RJ, Walsh CL, Purnell P and Rogers CDF (2014) Briefing: infrastructure business models, valuation and innovation for local delivery. Infrastructure Asset Management 1(3): 66-67.

Dunn N, Cureton P and Pollastri S (2015) A Visual History of the Future. Government Office for Science, London, UK. See http://www.gov.uk/government/publications/future-cities-a-visualhistory-of-the-future (accessed 31/01/2018).

EA (Environment Agency) (2006) Exploring the Future: Guidance Toolkit for Using Environment Agency Scenarios 2030. Environment Agency, London, UK. Science report: SC050002/SR2. 
Electris C, Raskin P, Rosen R and Stutz J (2009) The Century Ahead: Four Global Scenarios Technical Documentation. Tellus Institute, Boston, MA, USA.

Foresight (2003) Sustainable Water Management: A Future View. Sustainable Water Management Associate Foresight Programme, London, UK.

GOfS (Government Office for Science) (2004) Foresight - Future Flooding Report. Office of Science and Technology, London, UK. See http://www.gov.uk/government/publications/future-flooding (accessed 31/01/2018).

GOfS (2005) Foresight - Drugs Futures 2025: The Scenarios. Office of Science and Technology, London, UK. See http://www.gov.uk/ government/publications/drugs-futures-2025 (accessed 31/01/2018).

GOfS (2009) Scenario Planning: Guidance Note. The Government Office for Science, London, UK.

GOfS (2010) Global Food and Farming Futures. GOfS, London, UK See http://www.gov.uk/government/publications/future-of-food-andfarming (accessed 31/01/2018).

GOfS (2017a) The Futures Toolkit - Tools for Futures Thinking and Foresight Across UK Government. GOfS, London, UK. See http://www.assets.publishing.service.gov.uk/government/uploads/ system/uploads/attachment_data/file/674209/futures-toolkitedition-1.pdf (accessed 31/10/2018).

GOfS (2017b) Future of Cities: An Overview of the Evidence. GOfS, London, UK. See http://www.gov.uk/government/publications/ future-of-cities-overview-of-evidence.

GOfS (2018a) Future of Cities: Foresight for Cities. Government Office for Science, London, UK. See http://www.gov. uk/government/publications/future-of-cities-foresight-for-cities (accessed 31/01/2018).

GOfS (2018b) Foresight Projects. Government Office for Science, London, UK. See http://www.gov. uk/government/collections/foresight-projects (accessed 31/01/2018).

GOfS (2018c) Future of Cities: Science of Cities. GOfS, London, UK. See http://www.gov.uk/government/publications/future-of-citiesscience-of-cities (accessed 31/01/2018).

Hajkowicz S and Moody J (2010) Our Future World. An Analysis of Global Trends, Shocks and Scenarios. CSIRO, Canberra, Australia.

Hill G, Jones ET and Mclain R (2014) Aspirational Goals and Incremental Tools: Does Forecasting Exclude Other Frameworks for Strategic Planning? See http://www.publicsphereproject.org/events/ diac08/proceedings/18.Aspirational_Goals.Hill_et_al.pdf (accessed 20/05/2019).

Hirsh S (1985) Using the Myers-Briggs Type Indicator in Organizations. Psychological Press, Oakland, CA, USA.

HM Government (2014) The Futures Toolkit: Tools for Strategic Futures for Policy-Makers and Analysts. HM Government, London, UK.

Hunt DVL and Rogers CDF (2016a) Aspirational City Futures: A Short Review of Foresight Approaches. London, UK. See http://www.gov.uk/government/publications/future-of-citiesaspirational-scenarios (accessed 31/01/2018).

Hunt DVL and Rogers CDF (2016b) Aspirational City Futures: Three Models for City Living. London, UK. See http://www.gov. $\mathrm{uk} /$ government/publications/future-of-cities-aspirational-scenarios (accessed 31/01/2018).

Hunt DVL and Rogers CDF (2016c) Aspirational City Futures: Three Models for City Living - Workshops. London, UK. See http://www.gov.uk/government/publications/future-of-citiesaspirational-scenarios (accessed 31/01/2018).

Hunt DVL, Lombardi DR, Atkinson S et al. (2012) Using scenarios to explore urban UK futures: a review of the literature 1998 to
2011 - monograph. In Designing Resilient Cities: A Guide to Good Practice (EP103 - supplement CD-ROM).

IAF (Institute for Alternative Futures) (2015) Institute for Alternative Futures. IAF, VA, US. See http://www.altfutures.org/foresightservices/sustainability/Alexandria (accessed 20/5/2019).

iBUILD (2018) See https://research.ncl.ac.uk/ibuild/ (accessed $31 / 01 / 2018)$.

Inayatullah S (2008) Six pillars: futures thinking for transforming. Foresight 10(1): 4-21.

Inayatullah S (2011) City futures in transformation: emerging issues and case studies. Futures 43(7): 654-661.

Inayatullah S, Molitor GTT, Roubelat F et al. (2009) Scenario symposium. Journal of Futures Studies 13(3): 75-156.

Jung CG (1981) The Archetypes and the Collective Unconscious, 2nd edn, Princeton University Press, Princeton, NJ, USA.

Karlsen JE and Øverland EF (2012) Promoting diversity in long term policy development: the SMARTT case of Norway. Journal of Futures Studies 16(3): 63-78.

Leach JM, Braithwaite PA, Lee SE et al. (2016) Measuring urban sustainability and liveability performance: the city analysis methodology (CAM). International Journal of Complexity in Applied Science and Technology 1(1): 86-106.

Leach JM, Lee SE, Hunt DVL and Rogers CDF (2017) Improving city-scale measures of livable sustainability: a study of urban measurement and assessment through application to the city of Birmingham, UK. Cities 71: 80-87.

Leach JM, Rogers CDF, Ortegon-Sanchez A and Tyler N (2018) The liveable cities method: establishing the case for transformative change. Proceedings of the Institution of Civil Engineers Engineering Sustainability. (in press), https://doi.org/10.1680/ jensu.18.00028.

Leach JM, Mulhall R, Rogers CDF and Bryson JR (2019) Reading cities: developing an urban diagnostics approach for identifying integrated urban problems with application to the city of Birmingham, UK. Cities 86: 136-144.

Lombardi DR, Caserio M, Donovan R et al. (2011) Elucidating sustainability sequencing, tensions and tradeoffs in development decision-making. Environment and Planning B, Planning and Design 38(6): 1105-1121.

Lombardi DR, Leach JM, Rogers CDF et al. (2012) Designing Resilient Cities: A Guide to Good Practice (EP103). IHS BRE Press, Bracknell, UK.

Markley O (2015) Aspirational guidance for wiser futures: toward open-sourced ascension from ego-centric to ecocentric human communities. Foresight 17(1): 1-34.

Miles I (2005) Knowledge intensive business services: prospects and policies. Foresight 7(6): 39-63.

Myers IB and McCaulley MH (1985) Manual: A Guide to the Development and Use of the Myers-Briggs Type Indicator. Consulting Psychologists Press, CA, USA.

NERR (Natural England Research Report) (2009) England's Natural Environment in 2060 - Issues, Implications and Scenarios. Natural England Research Report, Worcester, UK, NERR031.

Ogilvy J (1995) Living without a Goal, 1st edn, Doubleday Business, New York, NY, USA.

OST (Office of Science \& Technology) (2002) Foresight Futures 2020: Revised Scenarios and Guidance. Office of Science \& Technology (OST), London, UK. See http://www.foresight.gov.uk (accessed 20/05/2019).

Pollastri S, Dunn N, Cooper RFD et al. (2018) Envisioning urban futures as conversations to inform design and research. Proceedings of the Institution of Civil Engineers - Urban Design and Planning 171(4): 146-156. 
Quenk NL (2000) Essentials of Myers-Briggs Type Indicator Assessment. Wiley \& Sons, New York, NY, USA.

Raskin P (2005) Global scenarios and the millennium ecosystem assessment: an historic overview. Ecosystems 8(2): 133-142.

Ratcliffe J and Krawczyk E (2011) Imagineering City Futures: the use of prospective through scenarios in urban planning. Futures 43: 642-653.

Ratcliffe J and Sirr L (2003) Futures Thinking for the Built Environment. The Prospective Process through Scenario Thinking for the Built and Human Environment: A Tool for Exploring Urban Futures. The Futures Academy, Dublin Institute of Technology, Dublin, Ireland.

Rogers CDF (2018) Engineering future liveable, resilient, sustainable cities using foresight. Proceedings of the Institution of Civil Engineers - Civil Engineering 171(6): 3-9, https://doi.org/10.1680/ jcien.17.00031.

Rogers CDF, Lombardi DR, Cooper RFD and Leach JM (2012) The urban futures methodology applied to urban regeneration, special issue on future proofing urban regeneration. Proceedings of the Institution of Civil Engineers - Engineering Sustainability 165(1): $5-20$.

Rogers CDF, Shipley J, Blythe P et al. (2014) Future Urban Living: A Report by the Policy Commission on Future Urban Living. The University of Birmingham, Birmingham, UK.
See http://www.birmingham.ac.uk/Documents/research/ policycommission/future-urban-living/future-urban-living-policycommission-report.pdf (accessed 31/01/2018).

Sadler JP, Grayson N, Hale JD et al. (2018) The Little Book of Ecosystem Services in the City - A Short Guide to Urban Metabolism and Resource Flows. Lancaster, UK. ISBN: 978-0-70442-956-7.

Schwartz P (1991) The Art of the Long View: Planning for the Future in an Uncertain World. Doubleday, New York, NY, USA.

Taylor CA, Crick R, Huang S, Davies R and Carhart N (2017) Learning frameworks for future infrastructure provision. Proceedings of the International Symposium for Next Generation Infrastructure (ISNGI 2017), London, UK, pp. 386-392.

UN (United Nations) (2015) Transforming Our World: The 2030 Agenda for Sustainable Development. UN, New York, USA.

Van der Heijden K (2005) Scenarios: The Art of Strategic Conversation. John Wiley \& Sons, Chichester, UK.

van Soest D, Tight MR and Rogers CDF (2019) Exploring the distances people walk to access public transport. Transport Reviews (in press), https://doi.org/10.1080/01441647.2019.1575491.

WEF (World Economic Forum) (2008) Engineering and Construction: Scenarios to 2020. World Scenario Series, World Economic Forum, Cologny, Switzerland.

Zadeh SM, Hunt DVL and Rogers CDF (2014) Socio-technological influences on water demands. Water 6(7): 1961-1984.

\section{How can you contribute?}

To discuss this paper, please email up to 500 words to the editor at journals@ice.org.uk. Your contribution will be forwarded to the author(s) for a reply and, if considered appropriate by the editorial board, it will be published as discussion in a future issue of the journal.

Proceedings journals rely entirely on contributions from the civil engineering profession (and allied disciplines). Information about how to submit your paper online is available at www.icevirtuallibrary.com/page/authors, where you will also find detailed author guidelines. 